\title{
Implicações das tecnologias de informação e comunicação no processo de educação permanente em saúde
}

\author{
Implications of information and communication technologies in the \\ process of permanent education in health
}

\section{Implicaciones de las tecnologías de la información y la comunicación en el proceso de educación permanente en salud}

Quitéria Larissa Teodoro Farias | larissa.teodoro1996@gmail.com

Universidade Estadual Vale do Acaraú. Sobral, Brasil.

Sibele Pontes Rocha | sibelepontes@hotmail.com

Universidade Federal do Ceará. Fortaleza, Brasil.

Ana Suelen Pedroza Cavalcante | anasuelen15@hotmail.com

Universidade Federal do Ceará. Fortaleza, Brasil.

Jamylle Lucas Diniz | jamylledz@hotmail.com

Universidade Estadual Vale do Acaraú. Sobral, Brasil.

Osmar Arruda de Ponte Neto | netoarruda@live.com

Universidade Federal do Ceará. Fortaleza, Brasil.

Maristela Inês Osawa Vasconcelos | miosawa@gmail.com

Universidade Estadual Vale do Acaraú. Sobral, Brasil.

\section{Resumo}

Este artigo objetiva compreender as implicações das tecnologias de informação e comunicação (TIC) no processo de educação permanente em saúde. Trata-se de uma revisão integrativa, realizada por meio de busca na Biblioteca Virtual em Saúde (BVS) e na Scientific Eletronic Library Online (SciELO), utilizando: os descritores "tecnologia da informação" e "educação a distância", e as palavras-chave "educação permanente" e "formação na saúde". A partir da aplicação dos critérios de inclusão e exclusão, restaram 15 artigos, que foram analisados por níveis de evidências e divididos em duas categorias: "a inserção das TIC no processo de educação permanente em saúde a partir da educação a distância" e "a relação entre tutor/participante como facilitadora no processo de educação permanente em saúde por meio das TIC”. Em suma, as TIC produzem implicações positivas no processo de educação permanente de profissionais da saúde, apesar de alguns desafios a serem superados.

Palavras-chave: educação a distância; educação permanente; formação em saúde; profissional de saúde; tecnologia da informação. 


\begin{abstract}
This article aims to understand the implications of information and communication technologies (ICT) in the process of permanent education in health. This is an integrative review accomplished through the search in the Virtual Health Library (BVS) and the Scientific Eletronic Library Online (SciELO), using: the descriptors "information technology" and "distance education", and the keywords "continuing education" and "health education". From the application of the inclusion and exclusion criteria, remained 15 articles, which were analyzed by levels of evidence and divided into two categories: "the insertion of the ICT in the process of permanent education in health using distance education" and "the relation between tutor/ participant as facilitator in the process of permanent education in health through the ICT". In short, ICT have positive implications in the process of continuing education of health professionals, despite some challenges to be overcome.
\end{abstract}

Keywords: distance education; permanent education; health education; health profissional; information technology.

\title{
Resumen
}

Este artículo tiene como objetivo comprender las implicaciones de las tecnologías de la información (TIC) y en el proceso de educación permanente en salud. Se trata de una revisión integradora, realizada por medio de la búsqueda en la Biblioteca Virtual en Salud (BVS) y en la Scientific Eletronic Library Online (SciELO), utilizando: los descriptores "educación a distancia" y "tecnología de la información" y las palabras clave "educación continua" y "formación en salud". De la aplicación de los criterios de inclusión y exclusión, 15 artículos se mantuvieron, los cuales fueron analizados por niveles de evidencia y fueron divididos en dos categorías: "la integración de las TIC en el proceso de educación permanente acerca de la salud en la educación a distancia" y "la relación entre el tutor/participante como facilitadora en el proceso de educación permanente en salud a través de las TIC". En resumen, las TIC producen efectos positivos en el proceso de educación permanente de profesionales de la salud, aunque algunos de los desafíos que deben ser superados.

Palabras clave: educación a distancia; educación permanente; la formación en salud; profesional en salud; tecnología de la información.

Contribuição dos autores: os autores são responsáveis por todo o texto.

Declaração de conflito de interesses: não houve.

Fontes de financiamento: Conselho Nacional de Desenvolvimento Científico e Tecnológico- CNPq.

Agradecimento/Contribuições adicionais: não há.

Histórico do artigo: Submetido: 29.fev.2017 | Aceito: 27.nov.2017 | Publicado: 29.dez.2017

Apresentação anterior: não há.

Licença CC BY-NC atribuição não comercial. Com essa licença é permitido acessar, baixar (download), copiar, imprimir, compartilhar, reutilizar e distribuir os artigos, desde que para uso não comercial e com a citação da fonte, conferindo os devidos créditos de autoria e menção à Reciis. Nesses casos, nenhuma permissão é necessária por parte dos autores ou dos editores. 


\section{Introdução}

O Sistema Único de Saúde (SUS) surge no Brasil em 1988, como forma de reestruturar o modelo de atenção à saúde do país e, em seu bojo, agrupa os princípios da universalidade, equidade e integralidade da assistência. Embora nesses 28 anos muito se tenha avançado, ainda há desafios a serem enfrentados, principalmente no que diz respeito à insuficiência dos setores de formação em atender as necessidades de qualificação profissional de forma a efetivar esses princípios ${ }^{1}$.

Baseado nessa necessidade, o Ministério da Saúde (MS), por meio da Portaria nº 198/GM/MS, de 13 de fevereiro de 2004, instituiu a Política Nacional de Educação Permanente em Saúde (PNEPS), a qual visa promover mudanças positivas nos processos de formação e desenvolvimento dos trabalhadores da saúde, à medida que agrega aprendizado, reflexão crítica sobre o trabalho e resolutividade da clínica, por meio da problematização da realidade e construção coletiva de soluções ${ }^{2,3}$.

Visando a um maior poder de resolução, satisfação e adequação das ações e dos serviços propostos às necessidades de saúde da população ${ }^{4}$, faz-se necessário que as práticas de educação permanente em saúde (EPS) sejam as mais variadas possíveis para que alcancem diferentes públicos e consequentemente seus objetivos. Dessa forma, e levando em consideração a incorporação das tecnologias no cotidiano das pessoas, desvela-se necessário refletir acerca da inserção das tecnologias de informação e comunicação (TIC) como mediadoras dessas práticas de EPS.

As TIC fazem parte da rotina dos indivíduos, seja nas atividades pessoais, nas profissionais e até mesmo nas de lazer. Assim, tanto no campo da saúde como em outras áreas, as TIC só têm a contribuir e transformar de maneira positiva os processos de trabalho no SUS, visto que, já são apontadas como facilitadoras de aprendizagem e multiplicadoras do ensino. Neste sentido, o Centro Regional de Estudos para o Desenvolvimento da Sociedade da Informação (Cetic.br) conduz dentro do Núcleo de Informação e Coordenação do Ponto BR (NIC.br), a produção de estatísticas e indicadores TIC com rigor técnico e internacionalmente comparáveis, de forma a oferecer à sociedade os dados sobre os impactos socioeconômicos das TIC, contribuindo para a criação de políticas públicas mais efetivas e eficazes, buscando o desenvolvimento da Internet no Brasil ${ }^{5}$.

Depois da PNEPS, surgiram algumas estratégias, buscando oferecer o suporte necessário para ampliação dos benefícios conquistados por meio da referida política, a partir das TIC, destacando-se: a Comissão Interministerial de Gestão da Educação na Saúde, o Programa Nacional de Telessaúde Brasil e a Universidade Aberta do SUS (UNA-SUS) ${ }^{6}$. Neste contexto, insere-se a Rede Universitária de Telemedicina (Rute) integrada ao Programa Nacional de Telessaúde Brasil Redes, que representa uma iniciativa da Secretaria de Gestão do Trabalho e da Educação em Saúde (SGTES) e do Ministério da Saúde, com o objetivo de contribuir para a melhoria do atendimento e da atenção básica no Sistema Único de Saúde (SUS), por meio da promoção da teleassistência e da teleducação, em uma parceria com a UNA-SUS de forma a facilitar o acesso às atividades de capacitação dos profissionais da área da saúde.

O uso desses recursos tecnológicos proporciona autonomia e responsabilidade pela aquisição do próprio conhecimento. Nesse sentido, além de possibilitar essa construção, os ambientes virtuais ainda auxiliam no desenvolvimento e no treinamento de habilidades tecnológicas, seja na modalidade presencial, na semipresencial ou na educação a distância (EAD) ${ }^{8}$.

Na segunda edição da pesquisa TIC Saúde, o Cetic.br apresenta resultados atualizados sobre o estágio de adoção das TIC nos estabelecimentos de saúde do Brasil e sua apropriação pelos profissionais da área. Além de incluir a identificação da infraestrutura de TIC disponível, o uso dos sistemas pode apoiar os serviços assistenciais e a gestão, as atividades realizadas, as habilidades dos profissionais e a compreensão de potencialidades e dificuldades para a adoção das TIC pelos profissionais. Nesse contexto, a pesquisa revelou que as atividades de educação a distância em saúde relacionadas ao telessaúde estão disponíveis em 
27\% das unidades de saúde com acesso à Internet e que as atividades de pesquisa a distância estão em 20\% deles. Cabe destacar que, nessas atividades, os estabelecimentos públicos superam os privados 5 .

Diante disso, justifica-se o presente estudo, tendo em vista que as TIC são um meio de aprendizagem crescente devido à expansão do acesso à Internet, ao seu baixo custo; a possibilidade de superar as barreiras geográficas, proporcionando a democratização do acesso à educação, torna-se relevante uma vez que se insere no processo de educação permanente de profissionais da saúde. Assim, o presente artigo tem como objetivo compreender as implicações das TIC no processo de EPS a partir de evidências encontradas nas produções científicas.

\section{Estratégia metodológica}

Tratase de uma revisão integrativa, método de pesquisa que possibilita a síntese do conhecimento em um assunto determinado, além de revelar lacunas do conhecimento que precisam ser preenchidas com o desenvolvimento de novos estudos, sendo também capaz de oferecer suporte para a tomada de decisões e a melhoria da prática clínica9.

Para o alcance do objetivo foram seguidas as seguintes fases: (1) elaboração da pergunta norteadora; (2) busca na literatura (utilizando critérios de inclusão e exclusão); (3) coleta de dados (por meio de instrumentos); (4) análise crítica dos estudos incluídos; (5) discussão dos resultados ${ }^{10,11}$.

Para guiar a revisão integrativa, foi estabelecida a seguinte questão norteadora: "Quais as implicações das TIC no processo de educação permanente em saúde?”.

A busca dos artigos foi realizada na Biblioteca Virtual em Saúde (BVS) e na Scientific Eletronic Library Online (SciELO), no período compreendido entre os meses de novembro de 2016 e janeiro de 2017. Foram selecionados dois descritores: "tecnologia da informação" e "educação a distância", extraídos do DeCS (Descritores em Ciências da Saúde) e duas palavras-chave: "educação permanente" e "formação na saúde". A escolha de palavras-chave justifica-se pela ausência de termos cadastrados no DeCS com o mesmo significado. Cabe salientar que a palavra-chave "formação na saúde" foi incluída para ampliar a busca, mas que o enfoque foi voltado para os aspectos formativos relacionados à educação permanente em saúde. Os termos foram associados em pares, realizando todos os cruzamentos possíveis, a fim de ampliar a busca nas referidas bases de dados.

Os critérios de inclusão adotados foram: a publicação apresentar temática pertinente ao contexto das TIC na educação permanente em saúde; ter como país de afiliação o Brasil; estar disponível eletrônica e gratuitamente na íntegra no idioma português. Foram excluídas as publicações duplicadas e/ou que não atendam aos critérios de inclusão previamente estabelecidos.

Neste artigo, optou-se pelo estudo das TIC e da educação permanente. Desta forma, todos os artigos que versavam sobre a educação continuada foram excluídos para evitar que os dois termos fossem tratados como sinônimos. A educação continuada é caracterizada por alternativas educacionais centradas no desenvolvimento profissional pessoal, ou seja, por meio de cursos ou especializações. Já a educação permanente em saúde consiste na problematização do processo de trabalho em saúde visando à transformação das práticas profissionais e da própria organização do trabalho ${ }^{12,13}$.

A busca realizou-se em ambas as bases de dados a partir dos seguintes cruzamentos: (1) "educação permanente" and "tecnologia da informação"; (2) "educação permanente" and "educação a distância"; (3) "educação permanente" and "formação na saúde"; (4) "tecnologia da informação" and "educação a distância"; "Tecnologia da Informação" and "Formação na Saúde", "Educação a distância" and "formação na saúde". As publicações foram selecionadas previamente pela leitura dos títulos e dos resumos, considerando os referidos critérios de inclusão e exclusão. Após esta análise, restaram as publicações que foram lidas na íntegra e analisadas de acordo com os critérios estabelecidos, a fim de constituir a amostra que faria parte da revisão. 
Para extrair os dados dos artigos selecionados, utilizou-se um instrumento previamente elaborado, de forma a minimizar o risco de erros e/ou omissão de dados na transcrição, garantindo a precisão das informações e funcionando como um registro ${ }^{14}$. Sendo assim, a coleta de dados foi realizada utilizando um instrumento validado por Ursi ${ }^{15}$ e adaptado pelos autores, no qual constam quatro eixos, a saber: a identificação do artigo, o tipo de publicação, as características metodológicas do estudo e a avaliação do rigor metodológico.

Os dados obtidos foram criteriosamente analisados e sistematizados, gerando duas categorias, a saber: a inserção das TIC no processo de educação permanente em saúde a partir da EAD, e a relação entre tutor/ participante como facilitadora no processo de educação permanente em saúde por meio das TIC. Por fim, os resultados foram sintetizados e discutidos a partir de literatura pertinente.

\section{Resultados e discussão}

Com o cruzamento dos descritores e palavras-chave, foram encontradas, na BVS, 416 publicações. Em relação ao tipo de documento foram localizados 257 artigos, 84 monografias, cinco congressos e conferências, 28 teses, cinco documentos não convencionais (informes técnicos, apresentações de congressos, planos de emergência), quatro documentos de projeto, 25 recursos da Internet, quatro recursos educacionais abertos e quatro vídeos. Após a aplicação dos filtros: texto completo disponível, idioma português e país de afiliação Brasil, restaram 41 artigos.

A partir da leitura dos títulos e resumos foram excluídas 21 publicações: 13 não possuíam relação direta com o tema; duas estavam escritas em inglês e seis estavam duplicadas. Após a primeira seleção pelos títulos e resumos, foi feita a leitura na íntegra, durante a qual, foram excluídos cinco artigos por tratarem da educação continuada, restando, portanto, 15 artigos, na referida base de dados.

Durante a busca na SciELO foram realizados os mesmos cruzamentos utilizados na BVS, resultando em 21 artigos. Após a aplicação dos filtros: texto completo disponível e idioma português, restaram sete publicações, e destas cinco foram excluídas pelo título, por estarem duplicadas e as duas restantes foram excluídas durante a leitura na íntegra por não tratarem da educação permanente e sim da continuada. No final restaram 15 artigos para integrarem a revisão, todos encontrados na Biblioteca Virtual em Saúde (BVS).

O Quadro 1 apresenta informações relevantes dos artigos selecionados para este estudo, com enfoque nas suas perspectivas metodológicas.

Quadro 1 - Amostra dos artigos selecionados para revisão por título, autor, ano, tipo de publicação, e metodologia. Sobral-CE, Brasil, 2017

\begin{tabular}{|l|l|l|l|l|l|}
\hline No & \multicolumn{1}{|c|}{ Título } & \multicolumn{1}{c|}{ Autor } & Ano & \multicolumn{1}{c|}{$\begin{array}{c}\text { Tipo de } \\
\text { Publicação }\end{array}$} & \multicolumn{1}{c|}{ Metodologia } \\
\hline 1 & $\begin{array}{l}\text { Formação permanente, } \\
\text { flexível e a distância pela } \\
\text { Internet: Curso de Gestão } \\
\text { Descentralizada de Recursos } \\
\text { Humanos em Saúde }\end{array}$ & $\begin{array}{l}\text { Struchiner M, Roschke } \\
\text { MA. }\end{array}$ & 2002 & Pedagogia & $\begin{array}{l}\text { Descritivo/ } \\
\text { qualitativo }\end{array}$ \\
\hline 2 & $\begin{array}{l}\text { Educação a distância para a } \\
\text { qualificação dos profissionais } \\
\text { do SUS: perspectivas e } \\
\text { desafios }\end{array}$ & Garcia RM, Baptista R. & 2007 & Pedagogia & $\begin{array}{l}\text { Relato de } \\
\text { experiência }\end{array}$ \\
\hline 3 & $\begin{array}{l}\text { Educação a distância como } \\
\text { estratégia para a educação } \\
\text { permanente em saúde: } \\
\text { possibilidades e desafios }\end{array}$ & Oliveira MAN. & 2007 & Enfermagem & $\begin{array}{l}\text { Descritivo/ } \\
\text { qualitativo }\end{array}$ \\
\hline
\end{tabular}


Quadro 1 - Amostra dos artigos selecionados para revisão por título, autor, ano, tipo de publicação, e metodologia. Sobral-CE, Brasil, 2017 (continuação)

\begin{tabular}{|c|c|c|c|c|c|}
\hline No & Título & Autor & Ano & $\begin{array}{c}\text { Tipo de } \\
\text { Publicação }\end{array}$ & Metodologia \\
\hline 4 & $\begin{array}{l}\text { Educação a distância: uma } \\
\text { ferramenta para educação } \\
\text { permanente de enfermeiros } \\
\text { que trabalham com } \\
\text { assistência perioperatória }\end{array}$ & $\begin{array}{l}\text { Ortiz MCL, Ribeiro LP, } \\
\text { Garanhani ML. }\end{array}$ & 2008 & Enfermagem & $\begin{array}{l}\text { Descritivo/ } \\
\text { qualitativo }\end{array}$ \\
\hline 5 & $\begin{array}{l}\text { A educação a distância como } \\
\text { dispositivo de fomento } \\
\text { às redes de cuidado em saúde }\end{array}$ & $\begin{array}{l}\text { Paulon SM, Carneiro } \\
\text { MLF. }\end{array}$ & 2009 & Psicologia & $\begin{array}{l}\text { Relato de } \\
\text { experiência }\end{array}$ \\
\hline 6 & $\begin{array}{l}\text { Compreendendo os } \\
\text { profissionais de Saúde da } \\
\text { Família como potenciais } \\
\text { estudantes na educação a } \\
\text { distância }\end{array}$ & $\begin{array}{l}\text { Tomaz JBC, Molen } \\
\text { HTVD }\end{array}$ & 2011 & Medicina & $\begin{array}{l}\text { Opiniões de } \\
\text { especialistas }\end{array}$ \\
\hline 7 & $\begin{array}{l}\text { Ensino a distância na } \\
\text { educação permanente em } \\
\text { urgência e emergência }\end{array}$ & $\begin{array}{l}\text { Tobase L, Tomazini } \\
\text { EAS, Teodoro SV, Piza } \\
\text { NRG, Peres HHC. }\end{array}$ & 2012 & Enfermagem & $\begin{array}{l}\text { Descritivo/ } \\
\text { qualitativo }\end{array}$ \\
\hline 8 & $\begin{array}{l}\text { O perfil de enfermeiros } \\
\text { fluminenses da ESF segundo } \\
\text { um Programa de educação } \\
\text { permanente a distância }\end{array}$ & $\begin{array}{l}\text { Faria MGA, David } \\
\text { HMSL, Acioli S. }\end{array}$ & 2012 & Enfermagem & $\begin{array}{l}\text { Descritivo/ } \\
\text { qualitativo }\end{array}$ \\
\hline 9 & $\begin{array}{l}\text { Consultorias online: uma } \\
\text { nova perspectiva no trabalho } \\
\text { da enfermagem }\end{array}$ & $\begin{array}{l}\text { Faria MGA, David } \\
\text { HMSL, Acioli S. }\end{array}$ & 2013 & Enfermagem & $\begin{array}{l}\text { Descritivo/ } \\
\text { qualitativo }\end{array}$ \\
\hline 10 & $\begin{array}{l}\text { Educação a distância e } \\
\text { formação continuada: em } \\
\text { busca de progressos para a } \\
\text { saúde }\end{array}$ & $\begin{array}{l}\text { Oliveira AEF, Ferreira } \\
\text { EB, Sousa RR, Junior } \\
\text { EFC, Maia MFL. }\end{array}$ & 2013 & Medicina & $\begin{array}{l}\text { Relato de } \\
\text { experiência }\end{array}$ \\
\hline 11 & $\begin{array}{l}\text { Teleamamentação no } \\
\text { Programa Nacional de } \\
\text { Telessaúde no Brasil: a } \\
\text { experiência datelenfermagem }\end{array}$ & $\begin{array}{l}\text { Prado C, Silva IA, } \\
\text { Soares AVN, Aragaki } \\
\text { IMM, Shimoda GT, } \\
\text { Zaniboni VF. et al. }\end{array}$ & 2013 & Enfermagem & $\begin{array}{l}\text { Relato de } \\
\text { experiência }\end{array}$ \\
\hline 12 & $\begin{array}{l}\text { Atenção básica e educação } \\
\text { permanente em saúde: } \\
\text { cenário apontado pelo } \\
\text { Programa Nacional de } \\
\text { Melhoria do Acesso e da } \\
\text { Qualidade da Atenção Básica } \\
\text { (PMAQ-AB) }\end{array}$ & $\begin{array}{l}\text { Pinto HÁ, Ferla AA, } \\
\text { Ceccim RB, Florêncio } \\
\text { AR, Barbosa MG, } \\
\text { Stélide NLR. et al. }\end{array}$ & 2014 & Medicina & $\begin{array}{l}\text { Descritivo/ } \\
\text { qualitativo }\end{array}$ \\
\hline 13 & $\begin{array}{l}\text { Avaliação da capacitação dos } \\
\text { enfermeiros em unidades } \\
\text { básicas de saúde por meio da } \\
\text { telenfermagem }\end{array}$ & $\begin{array}{l}\text { Godoy SCB, Guimarães } \\
\text { EMP, Assis DSS. }\end{array}$ & 2014 & Enfermagem & $\begin{array}{l}\text { Descritivo/ } \\
\text { qualitativo }\end{array}$ \\
\hline 14 & $\begin{array}{l}\text { Limites e possibilidades do } \\
\text { ensino a distância (EAD) na } \\
\text { educação permanente em } \\
\text { saúde: revisão integrativa }\end{array}$ & $\begin{array}{l}\text { Silva NA, Santos AMG, } \\
\text { Cortez EA, Cordeiro BC. }\end{array}$ & 2015 & Enfermagem & $\begin{array}{l}\text { Descritivo/ } \\
\text { qualitativo }\end{array}$ \\
\hline 15 & $\begin{array}{l}\text { Experiências de enfermeiros } \\
\text { na educação a distância: um } \\
\text { olhar sobre as dimensões } \\
\text { interação e autonomia }\end{array}$ & $\begin{array}{l}\text { Cavalcante RB, } \\
\text { Gontijo TL, Silva LTC, } \\
\text { Esteves CJS, Diniz FA, } \\
\text { Vasconcelos DD. }\end{array}$ & 2016 & Enfermagem & $\begin{array}{l}\text { Descritivo/ } \\
\text { qualitativo }\end{array}$ \\
\hline
\end{tabular}

Fonte: Elaborado pelos autores. 
As evidências dispostas nos artigos mostram que as discussões acerca da utilização das TIC nos processos de educação permanente dos profissionais da saúde estão presentes nas categorias de enfermagem, medicina, psicologia e pedagogia e se assemelham, na perspectiva de que a educação a distância possibilita o protagonismo dos participantes envolvidos, além de facilitar o acesso às capacitações em EPS, favorecendo a democratização do saber.

Notam-se a partir do Quadro 1 informações acerca da metodologia dos artigos utilizados para o estudo que, em sua maioria, consistem em estudos descritivos com abordagem qualitativa $\left(n^{0} 1,3,4,7,8,9,12,13\right.$, $14,15)$. Se levarmos em consideração que a maioria deles $\left(n^{0} 3,4,7,8,9,11,13,14,15\right)$ foram desenvolvidos pela categoria enfermagem, é nítido que pesquisas descritivas/qualitativas ainda prevalecem na realidade da mesma.

A abordagem qualitativa alcança uma aproximação fundamental e de intimidade entre sujeito e objeto de estudo, visto que ambos são da mesma natureza: esta se volve com empatia para os motivos, as intenções e os projetos dos atores, a partir dos quais as ações, as estruturas e as relações tornam-se significativas ${ }^{16}$, 0 que se relaciona intimamente com os processos de educação permanente, considerando que a subjetividade é essencial nesses dois conceitos.

Quanto ao ano de publicação, observa-se que sobressai o de $2013\left(\mathrm{n}^{\circ} 9,10,11\right)$, o que pode ser explicado pela elaboração neste mesmo ano da Pesquisa do uso das tecnologias de informação e comunicação nos estabelecimentos de saúde brasileiros - TIC Saúde 2013. Essa pesquisa concede informações pertinentes acerca da expansão das TIC nos diversos setores da área da saúde, inclusive no processo de educação permanente dos profissionais, ressaltando a importância das redes de telessaúde como um meio eficiente de fornecer educação permanente ${ }^{17}$, o que pode ter estimulado mais pesquisas acerca da temática e, consequentemente, mais publicações.

\section{A inserção das TIC no processo de educação permanente em saúde a partir da EAD}

O desenvolvimento de um SUS mais democrático, equitativo e eficaz está intimamente ligado ao conhecimento e à postura dos profissionais que o compõem. Neste sentido, ações de EPS são percebidas como mecanismos capazes de motivar os profissionais a trabalharem dentro da lógica da interdisciplinaridade, da integralidade e da clínica ampliada e, assim. produzir mudanças necessárias em seu perfil profissional ${ }^{17}$.

É possível compreender que, aliando esse processo à EAD, torna-se viável manter um programa de capacitação constante dos profissionais, aliado sempre às necessidades de aprendizagem que transformarão as práticas profissionais em saúde, fato que caracteriza a marca da EPS. Ao integrar as TIC aos processos de EPS é possível adquirir conhecimento no próprio local de trabalho ou em qualquer outro espaço que o profissional considere adequado, como na própria residência, sem atrapalhar suas atividades cotidianas, além de possibilitar a autonomia no processo de aprendizagem, tornando assim o sujeito protagonista de seu processo de ensino-aprendizagem.

Dentro da área da saúde, as TIC têm como finalidade a aplicabilidade na práxis, que necessita ser mais conhecida pelo ensino, melhorando a formação profissional, na busca pela qualificação no processo de aprendizagem. Seguindo essa lógica, isso oportuniza ao estudante conhecer e refletir sobre a complexidade na utilização dos instrumentos computacionais na organização e no funcionamento dos sistemas e serviços de saúde ${ }^{18}$.

Considerando a amostra das publicações incluídas nesta revisão, observamos que as implicações mais salientadas pelos autores acerca da inserção das TIC no processo de EPS, foram: o protagonismo dos participantes, evidenciado em sete artigos $\left(\mathrm{n}^{\circ} 2,3,4,5,6,9,11\right)$ e a facilidade de acesso, que se mostrou relevante em oito artigos $\left(\mathrm{n}^{\circ} 1,3,4,8,10,12,13,14\right)$. Neste sentido, cabe destacar que os processos de EPS 
têm se intensificado cada vez mais, a partir da incorporação dos mesmos em modalidade de EAD e com o auxílio das TIC, sendo a facilidade de acesso geográfico, um dos principais motivos desse achado.

A facilidade de acesso permite alcançar um elevado número de pessoas, a comparar com uma sala de aula presencial, além do baixo custo, ampliando assim as oportunidades para aqueles que estão limitados por tempo e/ou espaço insuficiente, de forma a estimular o raciocínio crítico e o protagonismo dos participantes, por meio da construção de uma aprendizagem significativa que, por sua vez, possibilita aos envolvidos a produção de seus próprios saberes, tanto individualmente por meio do acesso individual às informações, quanto coletivamente por meio dos ambientes de interação, intercâmbio de experiências e troca de valores que os módulos de EAD possibilitam.

Diante da complexidade para se efetivar a universalidade do SUS, com seus níveis de atenção e densidade tecnológica, é importante pensar que o acesso à Internet, bem como, a EAD, agem como potencializadores nas discussões sobre o modo de fazer EPS, como um ambiente capaz de se discutirem as práticas profissionais desenvolvidas, trocando saberes entre os educandos e os educadores e levando em consideração que a EPS é a premissa para garantir a melhoria das instituições e dos processos de trabalho em saúde ${ }^{19}$.

Além disso, foi possível verificar o destaque da categoria de enfermagem nas publicações selecionadas para o estudo. Vale ressaltar que tanto na prática quanto na teoria, os profissionais dessa área necessitam do uso das TIC para o aprimoramento de suas atividades, viabilizando a unificação de novos conhecimentos para essa categoria. Cardoso e colaboradores ${ }^{20}$ afirmam que o uso da Internet pelos profissionais da área de enfermagem ampliam e melhoram os seus níveis de informações, pois ela já faz parte do cotidiano desses profissionais, e, consequentemente, facilita o desenvolvimento do saber cultural, social e científico.

O ensino a distância passa por uma época de transformações, na qual a comunicação e as informações ganham incentivos para a incorporação de novas ideias que fortalecem o processo de educação permanente para os profissionais da saúde ${ }^{21}$. Foi possível verificar, diante dos artigos selecionados, que muitos desses profissionais possuem a necessidade de atualização e capacitação em determinados assuntos para dar continuidade às suas atividades. E, apesar da maioria desses achados estarem relacionados à categoria enfermagem, vale ressaltar que o ensino a distância pode potencializar os processos de trabalho de todos os profissionais de saúde e deve estar cada vez mais presente em seu cotidiano, possibilitando a inserção dos mesmos em cursos que os tornem protagonistas e responsáveis pelo seu processo de aprendizagem, de forma a qualificar suas práticas.

A utilização das TIC pelos profissionais de saúde funciona como uma das ferramentas que pode facilitar a aquisição de novos saberes e o compartilhamento dos conhecimentos prévios de cada participante. O caráter educacional, por sua vez, possibilita a curiosidade na busca de novos assuntos, proporcionando uma pesquisa mais ampliada, que facilita o processo de aprendizagem. Neste sentido, a educação permanente, como ferramenta de ensino tecnológico, é uma das estratégias que favorece a construção de um novo estilo na formação profissional, oportunizando aos indivíduos desenvolverem um raciocínio crítico e reflexivo dentro da área da saúde ${ }^{22}$.

Uma limitação encontrada nos estudos $\left(\mathrm{n}^{\circ} 3,12,15\right)$ foi a dificuldade de acesso às TIC por parte dos profissionais. Essa dificuldade estava relacionada principalmente à sua falta de habilidade para operar essas tecnologias, o que é reafirmado em outros artigos como uma responsabilidade das próprias instituições promotoras do ensino, bem como dos educadores mediadores desse processo de atuarem na readaptação dos educandos às novas formas de letramento, ou seja, de ensinar e aprender a ler e escrever, no contexto do letramento digital. Este, por sua vez, consiste no alcance de competências para interagir, produzir e compartilhar conteúdos em meio digital, utilizando as TIC para leitura, escrita e comunicação, dominando criticamente esse uso e permitindo julgar a confiabilidade e credibilidade das diferentes fontes de informação ${ }^{23,24}$. 
Amem e Nunes ${ }^{25}$ relacionam como uma estratégia dessa readaptação a importância dos encontros presenciais e o compromisso, por parte das instituições, de proporcionarem espaços de interação, onde educadores e educandos partilhem experiências e elaborem uma reflexão crítica sobre suas práticas e, desse modo, possam promover o autoconhecimento e a autoformação, por meio de um debate contínuo do processo de ensino-aprendizagem. Com a motivação de todos e a sua participação desse intuito, acredita-se que avanços importantes seriam possíveis nessa area.

Foi identificada também uma limitação, no que diz respeito ao acesso deficiente das TIC no ambiente de trabalho, com destaque para as regiões Norte e Nordeste e, apesar de representar um achado menor, pois apenas três artigos fazem essa ressalva, torna-se interessante discutir essa questão, pois embora a pesquisa elaborada pela TIC Saúde 2013 tenha observado que 94\% dos estabelecimentos de saúde tenham computadores e 91\% tenham acesso à Internet, ainda há essa lacuna principalmente no que diz respeito à atenção básica e ambulatorial, ou seja, aos locais onde não há internação, mas que também necessitam da utilização dessas tecnologias, tanto para atividades da própria gestão quanto para a educação permanente ${ }^{16}$.

\section{A relação entre tutor/participante como facilitadora no processo de educação permanente em saúde por meio das TIC}

Embora uma das maiores implicações observadas no estudo tenha sido o estímulo ao protagonismo e à autonomia dos participantes envolvidos nesse processo de $\mathrm{EP}$, alguns artigos $\left(\mathrm{n}^{\circ} 3,5,9,10,14,15\right)$ destacam que há necessidade da criação de vínculo entre tutores/participantes para alcançar esse objetivo, que fortalece o aprendizado e contribui para a continuidade das atividades. Isso se faz possível por meio de uma comunicação constante entre ambos, seja em encontros presenciais ou no próprio ambiente virtual em que o curso seja ofertado.

Segundo Barbosa e Rezende ${ }^{26}$, a tutoria é fundamental para o bom desempenho do participante em um curso EAD e, por esse motivo, tem sido objeto de estudo de diversos autores. Compreende-se que é, a partir do diálogo estabelecido entre tutor/participante, participante/participante com os instrumentos oferecidos nesse processo que ocorre a aprendizagem significativa; logo, torna-se possível inferir que implicado nesse vínculo encontra-se a efetividade da educação permanente, à medida que auxilia os participantes envolvidos a absorverem cada detalhe e os seus significados para posteriormente reproduzirem como cidadãos e profissionais os serviços da saúde atuantes na sociedade ${ }^{27}$.

Considerando que a aprendizagem é algo complexo, é importante que os tutores busquem promover a construção do conhecimento por parte dos próprios envolvidos, sendo ambos, autores de suas práticas e reflexões, principalmente quando se pretende utilizar as TIC como instrumentos que facilitem os processos de EPS. Mais do que interagir com os cursistas, o tutor atua como um mediador, acreditando no potencial de cada um dos participantes e os motivando, a fim de alcançarem seus objetivos profissionais e pessoais. Para que assim, sejam multiplicadores e produtores de práticas exitosas e façam diferença onde atuarem. A tutoria se faz como uma alternativa que facilita a EAD, pois por meio das TIC possibilita a reflexão sobre as dúvidas em qualquer lugar e horário ${ }^{27}$.

Verifica-se que, embora a EAD seja uma alternativa válida, acessível e prática, ainda há necessidade de um acompanhamento e comunicação efetivos para que haja essa troca de experiência e realmente possa ser levada em consideração a realidade de cada sujeito dentro de seu ambiente de trabalho. Dos artigos em estudo ( $\left.\mathrm{N}^{0} 3,5,9,10,14,15\right)$ que fazem ressalva para essa discussão, três abordam essa interação entre tutores/participantes como recomendação dos autores diante de estudos desenvolvidos nessa área; e três trazem essa falta de interação como uma limitação para a permanência dos participantes no curso, pois contribui para evasão. Porém, compreendem-se também as dificuldades que o tutor enfrenta para conseguir contemplar todas essas necessidades. 
Barbosa e Rezende ${ }^{26}$ justificam essa dificuldade devido à enorme sobrecarga imposta aos tutores, uma vez que estes precisam dar conta de todas as exigências que o processo educativo a distância impõe e, ainda, manter essa constante interação com os participantes que, na maioria das vezes, se torna insuficiente devido às questões culturais implicadas no processo educativo a distância, cultura essa aceitável se considerarmos que o brasileiro privilegia o contato físico, a comunicação e as relações de vizinhança, diferentemente da cultura europeia, na qual se orienta a EAD.

\section{Considerações finais}

Todas as publicações que integraram esta revisão foram artigos encontradas no BVS, a maioria publicada com a categoria enfermagem, no ano de 2013, e consistem em estudos descritivos com abordagem qualitativa. Além disso, cabe destacar que as principais implicações apontadas pelos autores acerca da inserção das TIC no processo de EPS foram: a facilidade de acesso e o protagonismo dos participantes envolvidos. Outra evidência encontrada foi a importância da relação entre tutores e participantes no processo de EPS, por meio das TIC.

A partir dos resultados deste estudo foi possível observar que as TIC são responsáveis por implicações positivas no processo de educação permanente de profissionais da saúde, dentro de sua amplitude e que, embora ainda haja desafios a serem superados, como a falta de investimento em alguns estabelecimentos de saúde e um maior acompanhamento dos tutores em relação aos participantes, é nítido que grandes avanços já foram alcançados. Entre eles, cabe destacar a facilidade de acesso às informações que as TIC possibilitam. Dessa forma, pode-se afirmar que as TIC surgem como uma das ferramentas inovadoras que podem facilitar o processo de ensino-aprendizagem

Porém, ainda não há estudos que destaquem uma forma de mensurar se esses processos de formação têm de fato transformado a realidade da prática profissional em serviço e é algo que, apesar de subjetivo, possibilitaria um aperfeiçoamento cada vez maior desses processos; sendo assim, sugere-se que novos estudos sejam delineados nessa perspectiva.

$\mathrm{O}$ fato de ainda estar muito presente na literatura o conceito de educação permanente como sinônimo da educação continuada pode ser algo que dificulta essa realidade e que trouxe limitações para o estudo, no sentido de redução da amostra, já que foram incluídas na revisão somente as publicações relacionadas à educação permanente. Logo, se compreende que há necessidade de produções atualizadas que incorporem as duas definições, considerando suas diferenças teóricas.

\section{Referências}

1. Machado JFFP, Carli AD, Kodjaoglanian VL, Santos MLM. Educação Permanente no cotidiano da Atenção Básica no Mato Grosso do Sul. Saúde debate. 2015; 39(104):102-13.

2. Moraes KG, Dytz JLG. Política de educação permanente em saúde: análise de sua implementação. ABCS Health Sci. 2015; 40(3):263-9.

3. Brasil. Ministério da Saúde. Portaria no 198/GM/MS, de 13 de fevereiro de 2004. Institui a Política Nacional de Educação Permanente em Saúde como estratégia do Sistema Único de Saúde para a formação e o desenvolvimento de trabalhadores para o setor e dá outras providências. Brasília: Ministério da Saúde; 2004.

4. Mishima SM, Aiub AC, Rigato AFG, Fortuna CM, Matumoto S, Ogata MN, et al. Perspectiva dos gestores de uma região do estado de São Paulo sobre educação permanente em saúde. Rev esc enferm USP. 2015; 49(4):665-73.

5. TIC Saúde 2014: [livro eletrônico]: pesquisa sobre o uso das tecnologias de informação e comunicação nos estabelecimentos de saúde brasileiros/ coordenador Alexandre F. Barbosa. 2 ed. São Paulo: Comitê Gestor da Internet no Brasil; 2015. 
6. Prado ML.Políticas e programas de educação permanente em saúde no Brasil: revisão integrativa de literatura. Saúde. \& Transformação Social. 2012; 3(2):113-28.

7. TIC Saúde 2014 [livro eletrônico]: pesquisa sobre o uso das tecnologias de informação e comunicação nos estabelecimentos de saúde brasileiros = ICT in health 2014: survey on the use of information and communication technologies in brazilian health care facilities / coordenador/coordinator Alexandre F. Barbosa. São Paulo: Comitê Gestor da Internet no Brasil; 2015.

8. Lima ARS,Saeger MMMT, Morais JJS, Andrade TS.Moodle como apoio ao ensino presencial: um estudo junto aos discentes de ciências contábeis da UFPB sobre esta metodologia de ensino. Educação, Gestão e Sociedade: Revista da Faculdade Eça de Queirós. 2015; 5(18):1-19.

9. Souza MT, Silva MC, Carvalho R. Revisão integrativa: o que é e como fazer. Einstein. 2010; 8(1 Pt 1): $102-6$

10. Polit DF, Beck $C T$. Using research in evidence-based nursing practice. In: Polit DF, Beck CT, editors. Essentials of nursing research. Methods, appraisal and utilization.Philadelphia (USA): Lippincott Williams \& Wilkins; 2006:457-94.

11. Ganong LH. Integrative reviews of nursing research. Res Nurs Health. 1987;10(1):1-11

12. Backes VMS, Schmidt SMS, Nietsche EA. Educação continuada: algumas considerações na história da educação e os reflexos na enfermagem. Texto Contexto enfermagem 2003; 12(1):80-88.

13. Brasil. Ministério da Saúde (MS). Secretaria-Executiva. Secretaria de Gestão do Trabalho e da Educação na Saúde. Glossário temático: gestão do trabalho e da educação na saúde. Brasília: Editora do Ministério da Saúde; 2009. (Série A. Normas e Manuais Técnicos)

14. Benefield LE. Implementing evidence-based practicein home care. Home Healthc Nurse. 2003; 21(12):804-11.

15. Ursi ES. Prevenção de lesões de pele no perioperatório: revisão integrativa da literatura. [dissertação]. Ribeirão Preto: Universidade de São Paulo, Escola de Enfermagem de Ribeirão Preto; 2005.

16. Minayo MCS. Pesquisa social: teoria, método e criatividade. 17.ed. Rio de Janeiro: Vozes, 2000.

17. TIC Saúde 2013: [livro eletrônico]: pesquisa sobre o uso das tecnologias de informação e comunicação nos estabelecimentos de saúde brasileiros. coordenador/coordinator Alexandre F. Barbosa. 2. ed. São Paulo: Comitê Gestor da Internet no Brasil, 2015.

18. Rio de Janeiro. Análise da Política de Educação Permanente do SUS (PEPS) implementada pelas Secretarias Estaduais de Saúde (SES). Coordenação Geral: Tânia França. Universidade do Estado do Rio de Janeiro. Instituto de Medicina Social. Rio de Janeiro; 2016.

19. Cezar DM, Costa MR, Magalhães CR. Educação à Distância como Estratégia de Educação Permanente em Saúde?. EmRede Rev de Educação à Distância. 2017; 4(1).

20. Cardoso JP, Rosa VA, Lopes CRS, Vilela ABA, Santana AS, Silva ST. Construção de uma práxis educativa em informática na saúde para ensino de graduação. Ciênc saúde coletiva. 2008; 13(1):283-8.

21. Aires MB, Raggi FCP. Contribuições das TIC na educação permanente para profissionais de enfermagem. Revista Referência, 2014.

22. Oliveira MAN. Educação a Distância como estratégia para a educação permanente em saúde: possibilidades e desafios. Rev bras enferm. 2007; 60(5):585-9.

23. Peters K. M-Learning: Positioning educators for a mobile, connected future. International Review of Research in Open and Distance Learning; 2007. 8:2.

24. Freitas MT. Letramento Digital e a Formação de Professores. Educação em Revista; 2010. 26(3):335-352.

25. Amem BMV, Nunes, LC. Tecnologias de Informação e Comunicação: Contribuições para o Processo Interdisciplinar no Ensino Superior. Revista Brasileira de Educação Médica; 2006. 30(3):171-80.

26. Barbosa MFSO, Rezende F. A prática dos tutores em um programa de formação pedagógica a distância: avanços e desafios. Interface- Comunic, Saúde, Educ. 2006; 10(20):473-86.

27. Silva JM, Ribas CCC, Knaut MSJ. A relação professor/aluno na EAD e a promoção da aprendizagem significativa. Revista Eletrônica do Curso de Pedagogia das Faculdades OPET, Dez. 2014; 1-10. 